Wayne State University

DigitalCommons@WayneState

Psychology Faculty Research Publications

Psychology

$1-1-2009$

\title{
Comorbid Chronic Pain and Depression: Who Is at Risk?
}

\author{
L. R. Miller \\ Wayne State University \\ Annmarie Cano \\ Wayne State University, acano@wayne.edu
}

\section{Recommended Citation}

Lisa Renee Miller, Annmarie Cano

Comorbid Chronic Pain and Depression: Who Is at Risk?

The Journal of Pain, Volume 10, Issue 6, June 2009, Pages 619-627

http://dx.doi.org/10.1016/j.jpain.2008.12.007

Available at: http://digitalcommons.wayne.edu/psychfrp/14

This Article is brought to you for free and open access by the Psychology at DigitalCommons@WayneState. It has been accepted for inclusion in

Psychology Faculty Research Publications by an authorized administrator of DigitalCommons@WayneState. 
This article is the author's final version after peer-review. A publisher version (Elsevier) of this article previously appeared in The Journal of Pain, (10(6), 2009), available at http://www.elsevier.com/wps/find/journaldescription.cws_home/623147/description\#descripti on.

\section{(c) $(9)$}

This article is licensed under a Creative Commons license

http://creativecommons.org/licenses/by-nc-nd/3.0/us/ 


\title{
Comorbid Chronic Pain and Depression: Who Is at Risk?
}

\author{
L.R. Miller and A. Cano \\ Dept. of Psychology, Wayne State University, USA.
}

This research was supported by grant K01 MH66975 and the Center for Urban Studies at Wayne State University.

Correspondence concerning this article should be addressed to Annmarie Cano, Department of Psychology, 5057 Woodward Avenue- $7^{\text {th }}$ Floor, Wayne State University, Detroit, MI 48202, http://sun.science.wayne.edu/ acano. Electronic mail may be sent to acano@wayne.edu. 


\section{Abstract}

The purpose of this study was to investigate the prevalence and demographic risk factors of chronic pain and its comorbidity with depression. Computer-assisted telephone interviewing was utilized to obtain a representative community sample in the state of Michigan $(\mathrm{N}=1,179)$. The prevalence of chronic pain due to any cause was $21.9 \%$. Approximately $35 \%$ of participants with chronic pain also had comorbid depression $(7.7 \%$ of the entire sample). Depression was not associated with pain types or sites. A multinomial regression analysis revealed several demographic correlates of chronic pain and depression. Participants with chronic pain or comorbid pain and depression were more likely to be older, female, employed less than full-time, and have less education than persons without either condition. Logistic regression analyses showed that younger participants were more likely to have comorbid pain and depression than chronic pain only. A similar but marginally significant effect was found for African-American participants. Compared to the depression only group, those in the comorbid group were more likely to be women and middle-aged. These findings provide additional evidence on the prevalence of comorbid pain and depression in the community and suggest that certain demographic groups with chronic pain may especially benefit from depression screenings.

Perspective. This article reports on the prevalence of chronic pain and co-occurring depression in a representative community sample. The high prevalence rates of pain and comorbid depression point to the clinical importance of assessing depression in chronic pain samples.

Keywords: Chronic Pain, Depression, Comorbidity, Risk Factors, Epidemiology 


\title{
Comorbid Chronic Pain and Depression: Who Is at Risk?
}

\author{
L.R. Miller and A. Cano
}

\section{Introduction}

The annual costs attributed to chronic pain and depression are estimated at $\$ 215$ billion [1] and $\$ 80$ billion [16], respectively. Furthermore, co-occurring (i.e., comorbid) chronic pain and depression is associated with more disability and a poorer prognosis than either condition alone [2, 4, 27]. While it is recognized that these disorders are costly on societal and personal levels, the research on chronic pain and its comorbidity with depression remains difficult to interpret because of methodological variations across studies. This study addresses these methodological issues and examines the prevalence and risk factors of chronic pain and depression in a community sample.

Prevalence estimates for chronic pain (i.e., pain lasting 3-6 months or longer) range from 9\% to $33 \%[2,6,11,17,28,29]$. A review of the literature revealed that depression is present in $31 \%$ to $100 \%$ of people with pain [31]. Other studies have shown that the prevalence of depression in pain ranges from $4 \%$ to $66 \%$ across retirement community [27], primary care [2], pain clinic [7], and community samples $[11,12,17,23,24,26,29]$. However, the research suffers from various limitations. For instance, several studies do not explicitly ask about pain duration (e.g., [12, 26, 27]). Other studies define chronic pain as pain lasting at least one month [23, 24]. Many studies use depression checklists that do not clearly map onto DSM-IV 3 diagnostic criteria (e.g., [2, 23, 24]). Two community studies of Canadian samples, one on back pain 11 and the other on various conditions [29], addressed these various methodological issues and found that the prevalence of depression in a community sample of persons with chronic pain is approximately $11 \%$ to $20 \%$. Additional research is needed to establish whether rates of chronic pain and depression in other community samples are comparable using similar definitions of chronicity and depression.

Despite the problems noted above, several studies have been conducted on the risk factors for pain and depression. Pain prevalence rates are higher among women [10, 11, 23, 32, 34], Caucasians [10, 11], and among those with lower incomes, unemployment, and less education [6, 10, 23]. However, only two of these studies examined correlates of chronic pain $[6,11]$. In terms of depression risk factors, Magni and colleagues found that various demographic factors (e.g., sex, income, education) and the presence of pain predicted high levels of depressive symptoms [23-25]. However, differential correlates of chronic pain versus comorbid illness were not explored. The findings on gender as a correlate of comorbid depression are mixed. Women with pain may be at a higher risk for depression [29] while other research fails to show an association [2]. Furthermore, in a study of depressed 
outpatients, younger, African American, Hispanic, or less educated people were more likely to report pain [20]. While this study did not include participants with chronic pain in the absence of depression, it suggests that demographic variables might relate to comorbidity. As with studies on prevalence, methodological differences hamper efforts to identify the correlates of chronic pain and depression.

This study examined the prevalence rates of chronic pain, depression, and comorbid illness in a representative community sample. Chronic pain was defined as pain of at least 6 months and items from a standardized interview for major depression were used. The current study also investigates the differential demographic risk factors for chronic pain, depression, and comorbid chronic pain and depression. Thus, this study also makes a contribution to the literature by determining which persons with chronic pain are most likely to experience concomitant depression.

\section{Materials and Methods}

\section{Participants and Procedure}

This study was approved by the university's institutional review board. Wayne State University's Center for Urban Studies (CUS) used computer-assisted telephone interviewing (CATI) to collect the data. Two rounds of data collection occurred. In the first round of data collection, a random-digit dialing sample of 9,000 Michigan residences was procured from Survey Sampling, Inc. (SSI), sampled to represent proportionally the state's 83 counties. The sample was purged of known business numbers, and was run through SSI's random digit dialer to purge some disconnected numbers. A total of 7,111 numbers were imported into Sawtooth Technology's WinCATI software, used by CUS for all of its CATI surveys. Fifteen to twenty trained CATI interviewers were briefed on the study before beginning the project, and calls were made between 11/29/06 and 1/21/07. The first round of CATI obtained 660 participants.

A second round of data collection was conducted to recruit additional participants. In the second round of data collection, CUS research staff utilized two survey modes, telephone surveys and mail surveys. Trained telephone interviewers called through the purchased random digit dial sample approximately 10 times, achieving approximately 550 participants between 2/5/07 and 5/9/07. In addition to the telephone surveys, approximately 95 mail surveys were returned. However these participants are not included in analyses because of the small number who returned the mailed survey and because those who responded by mail were significantly different from the group that responded via telephone on race and gender. Specifically, men $\left(x^{2}(1, N=1312)=6.80, p<.01\right)$ and Caucasians $\left(\mathrm{x}^{2}(1, \mathrm{~N}=1211)=5.63, \mathrm{p}<.05\right)$ were more likely to respond by mail. 
When a respondent was reached, the interviewer asked to speak to the individual in the home who was at least 18 years old and most recently had a birthday. If the identified eligible respondent was not available, interviewers would try calling back up to 9 times. If the line was busy or an answering machine came on, 9 call backs were attempted. If the respondent was available, the interviewer provided an explanation of the purpose of the study and obtained verbal informed consent. The interviewer then proceeded to obtain demographic information and conduct the rest of

the survey. In addition to the survey presented in the current study, the other two sections of questions dealt with government funding of municipal services attitudes about dating violence among teens. The average length of a completed interview was 25 minutes. Respondents were provided with the opportunity to speak to a supervisor if they had any concerns or questions regarding the study. For quality purposes, $10 \%$ of the completed interviewers were analyzed for completeness and errors.

Throughout the first round of data collection, 6,885 phone numbers were utilized and in the second round of data collection, there was a total of 5,588 phone numbers. Based on the proportion of completed interviews to partial interviews and households refusing to participate or breaking off the conversation, the first round of CATI had a response rate of $28.3 \%$ and the second round had a response rate of $28.7 \%$.

\section{Measures}

Chronic pain questions. To determine if a participant suffered from chronic pain, two questions were asked: "For purposes of this study a chronic pain condition is defined as a condition that occurs daily, for most of the day, for at least 6 months. Has a health care professional diagnosed you with a chronic pain condition that you are living with currently?" and "How long have you had this chronic pain?" Participants were deemed as having chronic pain if they answered in the affirmative to the first question and reported that the pain lasted for at least six months. The six month criterion was chosen to be consistent with previous studies of chronic pain prevalence [2, 11, 28, 29]. Participants were asked to identify the types of chronic pain as well as the locations where they experienced chronic pain.

Depression. The Major Depressive Episode module of the Structured Clinical Interview for DSMIV-TR (SCID) [14] was used to assess major depression. Participants were read the 9 depressive symptom items found in the interview and were asked to report on the presence or absence of these symptoms over the past 2 weeks. In keeping with the DSM-IV-TR criteria, participants were labeled as having probable depression if they endorsed at least five of the nine items. At least one of these symptoms had to be "feeling down, depressed, or hopeless" or "little interest or pleasure in doing 
things." The term "probable depression" is used because interviews were not recorded to calculate inter-rater reliability. However, inter-item reliability was adequate $(\alpha=.79)$.

\section{Analytic Strategy}

Frequency analyses were first conducted to examine the prevalence of chronic pain types and pain sites. Frequency analyses were also conducted to determine the rate of comorbid chronic pain. In addition, chi-square analyses were conducted to investigate whether types and pain sites differed in participants with chronic pain alone from those with comorbid chronic pain and depression.

A multinomial logistic regression was used to determine which demographic variables are risk factors for a chronic pain only group, probable depression only group, and comorbid chronic pain and probable depression group when compared to those with the absence of chronic pain and probable depression. The demographic risk factors examined were age, race, gender, education, employment, and income. Age consisted of three groups: young (18-39), middle (40-59), and older adults (60+). The young group was the reference group. Race consisted of two groups; Caucasians and African Americans. African Americans were the reference group. Other ethnic/racial groups were excluded since relatively few participants endorsed these other categories. Additional analyses were run comparing Caucasians and non-Caucasians and the results were similar with the exception of the analysis comparing chronic pain only and comorbid groups. In this analysis, race was no longer significant. However, we present the analyses comparing just the two racial groups because grouping all non-Caucasian participants would result in a group that is even more heterogeneous, leading to potential problems in interpretation. Males were the reference group for gender. Educational groups were based on naturally occurring markers of educational level in the United States: high school or less, post-high school degree including Associate's and technical college degrees and certificates, bachelor's degree, and post-bachelor's degree. Post-bachelor's degree was the reference group. Employment consisted of two groups; full time employment (the reference group) and not full time employment. The two income groups consisted of those with personal annual earnings below or above $\$ 35,000$, with the latter being the reference category. According to U.S. census data in the year 2000, $\$ 35,000$ was the median individual income in Michigan.

Finally, three logistic regression analyses were used to determine if there were different demographic correlates for pairs of diagnostic groups: 1) chronic pain only vs. probable depression only; 2) chronic pain only vs. comorbid chronic pain and probable depression; and 3) probable depression vs. comorbid chronic pain and probable depression. The categories for the demographic variables were the same for these analyses as for the multinomial regression. For all logistic regression analyses, the odds ratios were reported with 95\% confidence intervals. Marginally 
significant results (i.e., $\mathrm{p}<.06$ ) are also considered if they are consistent with other findings in the current study, or if they are consistent with the existing literature.

\section{Results}

\section{Sample Characteristics}

The participants in this study were 1,179 adults residing in the state of Michigan. The sample was predominantly female $(62.1 \% ; \mathrm{n}=732)$ with a mean age of $51.06(\mathrm{SD}=16.21)$. Participants were asked to identify the racial group with which they self-identified. Nineteen (1.6\%) participants did not identify their racial group identification. The majority of the participants identified themselves as Caucasian (82.7\%; $\mathrm{n}=975$ ), followed by African American (10.4\%; $\mathrm{n}=123$ ), with the remainder self-identified as Latino/Hispanic (1.9\%; $\mathrm{n}=22)$, American Indian/Aleut/Eskimo (1.4\%; $\mathrm{n}=16)$, Asian/Pacific Islander (.6\%; $\mathrm{n}=7)$, Arab/Middle Eastern $(.3 \% ; \mathrm{n}=4)$, and other primary race or ethnic origin $(1.1 \% ; n=13)$. The majority of respondents were married $(57.4 \% ; n=677), 16.6 \%(n=$ 196) were never married, $12.3 \%(\mathrm{n}=145)$ were divorced, $10.9 \%(\mathrm{n}=128)$ were widowed, $1 \%(\mathrm{n}=12)$ were separated, and 1\% $(\mathrm{n}=11)$ were cohabiting, although .9\% $(\mathrm{n}=10)$ did not report marital status.

For the highest degree of education obtained, 3.8\% $(\mathrm{n}=45)$ responded none, $41.1 \%(\mathrm{n}=484)$ had a high school diploma or GED, 3.6\% $(\mathrm{n}=42)$ had an apprenticeship certificate, $8.2 \%(\mathrm{n}=96)$ had an associate degree from an occupational/vocational program, 8.1\% $(n=96)$ had an associate degree from an academic program, 19.7\% $(\mathrm{n}=232)$ had a bachelor's degree, $12.5 \%(\mathrm{n}=147)$ had a master's degree, $.9 \%(\mathrm{n}=11)$ had earned a professional degree, $1.3 \%(\mathrm{n}=15)$ had obtained a doctorate, and $.4 \%(\mathrm{n}=5)$ selected other. Six $(.5 \%)$ participants did not report their highest degree earned. For employment status, 39.8\% $(\mathrm{n}=469)$ worked full time, $13.6 \%(\mathrm{n}=160)$ worked part time, 30.3\% $(\mathrm{n}=$ $357)$ were retired, $14 \%(\mathrm{n}=165)$ were home-makers, $5.9 \%(\mathrm{n}=70)$ were students, $6.1 \%(\mathrm{n}=72)$ were unemployed, and 5.2\% $(\mathrm{n}=61)$ selected other. The total for employment status is greater than $100 \%$ because participants could select more than one category. Participants were asked to choose if their income was greater or less than $\$ 35,000$. Forty four percent $(n=519)$ reportedly earned less than $\$ 35,000$ and $42.7 \%(\mathrm{n}=503)$ earned more than $\$ 35,000$, which was the median individual income in Michigan in the 2000 census. Approximately thirteen percent $(n=157)$ of respondents declined to provide income information.

\section{Chronic Pain: Prevalence, Types, and Sites}

The overall chronic pain prevalence in this sample was $21.9 \%(n=259)$. A number of different types of chronic pain were endorsed (see Table 1). The most prevalent chronic pain types in the total sample was Osteoarthritis $(\mathrm{OA} ; 10.4 \%)$, followed by spine or disc problems $(9.1 \%)$, nerve pain $(5.3 \%)$, 
pain due to autoimmune conditions (4\%) and fibromyalgia (2.3\%). Approximately $16.5 \%(\mathrm{n}=194)$ of the sample reported chronic musculoskeletal pain, which was computed by combining the number of participants who reported OA, fibromyalgia, spine/disc problems, and other conditions like osteoporosis. It is acknowledged that this a rough estimate of those with chronic musculoskeletal pain.

\begin{tabular}{lccr}
\hline \multicolumn{1}{c}{ Chronic Pain Types } & Prevalence \\
\multicolumn{1}{c}{ Overall Sample \%a } & \multicolumn{2}{c}{ Chronic Pain \%b } & (n) \\
\hline Osteoarthritis & 10.4 & 47.5 & 123 \\
Spine or disc problems & 9.1 & 41.3 & 107 \\
Nerve problems & 5.3 & 23.9 & 62 \\
Autoimmune syndromes & 4.0 & 18.1 & 47 \\
Fibromyalgia & 2.3 & 10.4 & 27 \\
Abdominal conditions & 1.4 & 6.2 & 16 \\
Cancer & .8 & 3.9 & 10 \\
Blood related disorders & .4 & 1.9 & 4 \\
Skin diseases & .3 & 1.5 & 26 \\
Other & 2.2 & 10.0 & 3 \\
Don't know & .3 & 1.2 & \\
& & & \\
& & &
\end{tabular}

Note. The total number of pain types is greater than 259 because participants could endorse more than one type of pain. Of those with chronic pain, the percentages listed refer to the specific pain diagnoses.

Table 1. Prevalence of Chronic Pain Types.

Among those with chronic pain, almost half reported OA, approximately $65.6 \%$ reported back problems, and 74.9\% $(\mathrm{n}=194)$ reported chronic musculoskeletal pain. Nevertheless, $10 \%(\mathrm{n}=26)$ of those with chronic pain reported a condition not listed in the telephone interview (e.g., migraine headaches $)$ and $1.1 \%(\mathrm{n}=3)$ did not know their diagnosis. In terms of pain duration, 34.5\% $(\mathrm{n}=89)$ reported chronic pain of more than 10 years duration, 33.3\% $(\mathrm{n}=86)$ reported pain lasting 4 to 10 years, $26.4 \%(\mathrm{n}=68)$ reported pain lasting 1 to 3 years, and $5.8 \%(\mathrm{n}=15)$ reported their pain existed for six to eleven months.

Participants who reported chronic pain selected one or more sites where they experienced chronic pain. Table 2 displays the chronic pain sites. The most common sites of pain were the lower back $(60.6 \% ; \mathrm{n}=157)$, knee $(41.3 \% ; \mathrm{n}=107)$, hip $(34.4 \% ; \mathrm{n}=89)$, and ankle/foot $(34.0 \% ; \mathrm{n}=88)$. However, when lower and upper back pain reports were combined to create a back pain category, 63\% $(\mathrm{n}=$ 
146) of persons with chronic pain reported back pain. Of those with chronic pain, most participants reported 1 pain site $(29.7 \%, \mathrm{n}=77)$, with $23.6 \%(\mathrm{n}=61)$ reporting two pain sites, $11.2 \%(\mathrm{n}=29)$ reporting three pain sites, and $10.4 \%(n=27)$ reporting four pain sites. Approximately $25 \%(n=65)$ reported five or more pain sites.

\begin{tabular}{lrr}
\hline \multicolumn{1}{c}{ Pain Site } & \multicolumn{2}{c}{ Prevalence } \\
& & (n) \\
\hline Lower back & 60.6 & 157 \\
Knee & 41.3 & 107 \\
Hip & 34.4 & 89 \\
Ankle/foot & 34.0 & 88 \\
Shoulder & 33.2 & 86 \\
Neck & 30.5 & 79 \\
Wrist or hand & 29.7 & 77 \\
Upper back & 23.9 & 62 \\
Elbow & 13.5 & 35 \\
Leg & 5.0 & 13 \\
Head & 4.2 & 11 \\
Abdomen/pelvis & 3.1 & 8 \\
Other & 5.0 & 13 \\
\end{tabular}

$$
\mathrm{N}=259 .
$$

Note. The percentages are greater than $100 \%$ and the total pain sites are greater than 259 because each participant could endorse more than one pain site.

Table 2. Chronic Pain Prevalence By Pain Site.

\section{Comorbid Chronic Pain and Depression: Prevalence, Types, and Sites}

The majority of participants $(73.5 \% ; \mathrm{n}=866)$ did not report chronic pain or symptoms consistent with probable depression. The prevalence of chronic pain only (without depression) was $14.2 \%$ of participants $(n=168)$. Depression alone was found in $4.6 \%(n=54)$ whereas comorbid chronic pain and depression was present in $7.7 \%(\mathrm{n}=91)$ of the entire sample. Of those with chronic pain, 35.1\% ( $\mathrm{n}=91)$ had probable depression.

Analyses were conducted to determine if the distribution of musculoskeletal and nonmusculoskeletal diagnoses differed for the chronic pain groups. Separate groups were not compared because of the low frequencies of some of the separate pain types. The likelihood of musculoskeletal pain only vs. non-musculoskeletal pain (with $[\mathrm{n}=1]$ or without a co-occurring musculoskeletal pain condition) was similar across the chronic pain only and the comorbid chronic pain and depression groups, $(\square 2(1, \mathrm{~N}=259)=.06, \mathrm{p}>.05)$. A similar chi-square analysis was conducted to determine if pain sites were significantly different among those with chronic pain only and those with comorbid chronic pain and depression. The three pain site groups with the largest number of participants 
consisted of: 1) neck/back only, 2) lower extremity (knee, hip, ankle/foot, leg), and 3) upper extremity (wrist, elbow, shoulder, arms). The latter two groups could have reported neck or back pain as well. The prevalence of depression among those with chronic pain only and those with comorbid chronic pain and probable depression did not differ among pain site groupings $(\square 2(2, \mathrm{~N}=231)=2.36, \mathrm{p}>$ .05). When the analysis was repeated to compare anyone with neck/back pain regardless of other pain sites with participants in the other two groups (i.e., lower extremity with or without upper extremity) and upper extremity only, the results were similar $(\square 2(2, \mathrm{~N}=234)=1.42, \mathrm{p}>.05)$.

\section{Demographic Correlates of Comorbid Chronic Pain and Depression}

Multinomial Logistic Regression. The sample size is lower for this analysis than in previous sections because of missing data on at least one demographic variable $(n=173)$ or identification with a racial group other than Caucasian or African American $(n=57)$. Therefore, the sample for this analysis consisted of 949 participants; 683 with neither chronic pain nor depression, 139 participants with chronic pain only, 47 participants with depression only, and 80 participants with both chronic pain and depression. Chi-square analyses demonstrated that non-inclusion in the regression analyses was associated with a lower likelihood of depression. Specifically, 21\% $(n=218)$ of those without probable depression were dropped from the analyses compared to $12 \%$ ( $\mathrm{n}=18)$ of those with probable depression, $\mathrm{X}^{2}(1, \mathrm{~N}=1179)=6.15, \mathrm{p}<.02$. Rates of chronic pain were similar among those with and without missing data $\left(x^{2}(1, N=1179)=1.06, p>.30\right)$. Rates of depression and rates of chronic pain were similar among those with missing data and those reporting a nonincluded racial group identification, $\left(\mathrm{x}^{2}[1, \mathrm{~N}=236]=.44, \mathrm{p}>.50\right.$ and $, \mathrm{X}^{2}[1, \mathrm{~N}=236]=1.02, \mathrm{p}>$ .31 respectively).

Relative to persons without chronic pain or depression, people with chronic pain only were more likely to fall into the 60 years and over group ( $\mathrm{OR}=6.29 ; \mathrm{CI}=3.14,12.60 ; \mathrm{p}<.01)$ and the 40-59 age group $(\mathrm{OR}=4.17 ; \mathrm{CI}=2.11,8.21 ; \mathrm{p}<.01)$ than the youngest age group (See Table 3). Further, women and those employed less than full-time were more likely to have chronic pain $(\mathrm{OR}=1.78$; CI $=1.15,2.74 ; \mathrm{p}<.01 ; \mathrm{OR}=1.81 ; \mathrm{CI}=1.12,2.94 ; \mathrm{p}<.05$, respectively). Having less than a postbachelor's degree was also associated with chronic pain (high school or less OR = 3.03; CI = 1.52, $6.04 ; \mathrm{p}<.01 ;$ post-high school degree $\mathrm{OR}=2.64 ; \mathrm{CI}=1.24,5.64 ; \mathrm{p}<.05 ;$ bachelor's degree OR = 2.24; $\mathrm{CI}=1.06,4.75 ; \mathrm{p}<.05)$. 


\begin{tabular}{|c|c|c|c|c|c|c|}
\hline & \multicolumn{2}{|c|}{$\begin{array}{l}\text { Chronic Pain Only } \\
\quad(n=139)\end{array}$} & \multicolumn{3}{|c|}{$\begin{array}{l}\text { Depression Only } \\
(\mathrm{n}=47)\end{array}$} & \multirow{2}{*}{$\begin{array}{l}\begin{array}{l}\text { Comorbid } \\
(\mathrm{n}=80)\end{array} \\
\quad 95 \% \mathrm{CI}\end{array}$} \\
\hline & $\overline{\mathrm{OR}}$ & $95 \% \mathrm{CI}$ & OR & $95 \% \mathrm{CI}$ & OR & \\
\hline $\begin{array}{l}\text { Age } \\
\text { Old (60+) } \\
\text { Middle (40-59) } \\
\text { Young (18-39) }\end{array}$ & $\begin{array}{l}6.29 \\
4.17\end{array}$ & $\begin{array}{l}(3.14,12.60) \\
(2.11,8.21)\end{array}$ & $\begin{array}{l}.62 \\
.82\end{array}$ & $\begin{array}{l}(.27,1.43) \\
(.40,1.66)\end{array}$ & $\begin{array}{l}1.13 \\
4.20\end{array}$ & $\begin{array}{l}(.49,2.58) \\
(2.11,8.32)\end{array}$ \\
\hline $\begin{array}{l}\text { Gender } \\
\text { Female } \\
\text { Male }\end{array}$ & 1.78 & $(1.15,2.74)$ & .63 & $(.33,1.17)$ & 1.90 & $(1.06,3.40)$ \\
\hline $\begin{array}{l}\text { Race } \\
\text { Caucasian } \\
\text { African American }\end{array}$ & .99 & $(.50,1.95)$ & .62 & $(.26,1.48)$ & .49 & $(.25, .96)$ \\
\hline $\begin{array}{l}\text { Employment } \\
\text { Not full-time } \\
\text { Full-time }\end{array}$ & 1.81 & $(1.12,2.94)$ & 2.24 & $(1.07,4.66)$ & 3.79 & $(2.00,7.19)$ \\
\hline $\begin{array}{l}\text { Education } \\
\text { High school or less } \\
\text { Post-high school degree } \\
\text { Bachelor's degree } \\
\text { Post-bachelor's degree }\end{array}$ & $\begin{array}{l}3.03 \\
2.64 \\
2.24\end{array}$ & $\begin{array}{l}(1.52,6.04) \\
(1.24,5.64) \\
(1.06,4.75)\end{array}$ & $\begin{array}{r}2.00 \\
2.13 \\
.35\end{array}$ & $\begin{array}{l}(.71,5.61) \\
(.71,6.42) \\
(.07,1.83)\end{array}$ & $\begin{array}{l}6.81 \\
4.30 \\
3.73^{\dagger}\end{array}$ & $\begin{array}{r}(1.82,21.05) \\
(1.16,15.91) \\
(.99,14.08)\end{array}$ \\
\hline $\begin{array}{l}\text { Income } \\
\text { Below } \$ 35,000 \\
\text { Above } \$ 35,000\end{array}$ & .94 & $(.65,1.60)$ & 1.27 & $(.62,2.59)$ & 1.69 & $(.93,3.09)$ \\
\hline
\end{tabular}

$\mathrm{N}=949$.

Note. Reference group = absence of chronic pain and probable depression $(\mathrm{n}=683)$. Bold values indicate Odds Ratio (OR) significant at $\mathrm{p}<.05$. $\dagger \mathrm{OR}$ marginally significant at $\mathrm{p}<.06$.

Table 3. Multinomial Logistic Regression of Demographic Risk Factors.

There were similar differences between persons with comorbid chronic pain and depression and those without either condition. Those at risk for comorbidity compared to those without either condition were more likely to be in the 40-59 year age group than 18-39 (OR = 4.20; CI = 2.12, 8.32; $\mathrm{p}<.01)$, female $(\mathrm{OR}=1.90 ; \mathrm{CI}=1.06,3.40 ; \mathrm{p}<.05)$, and work less than full time (OR = 3.79; CI = $2.00,7.19 ; \mathrm{p}<.01)$. Participants with comorbidity were more likely to have an education of high school or less $(\mathrm{OR}=6.18 ; \mathrm{CI}=1.82,21.05 ; \mathrm{p}<.01)$, a post-high school degree $(\mathrm{OR}=4.30 ; \mathrm{CI}=1.16$, 
$15.91 ; \mathrm{p}<.05)$ than a post-bachelor's degree. A similar but marginally significant finding was found for participants with a bachelor's degree $(\mathrm{OR}=3.73$; $\mathrm{CI}=.97,14.08 ; \mathrm{p}<.06)$. However, there was also a racial group difference. Relative to those without either chronic pain or probable depression, those in the comorbid group were more likely to be African American $(\mathrm{OR}=.49 ; \mathrm{CI}=.25, .96 ; \mathrm{p}<$ $.05)$.

The only significant difference between people with depression only and people without depression or chronic pain was that the former were more likely to be employed less than full-time $(\mathrm{OR}=2.23$; $\mathrm{CI}=1.07,4.66 ; \mathrm{p}<.05)$.

Binary Logistic Regressions. Logistic regression analyses were then performed to compare the pairs of the three diagnostic groups: chronic pain only, depression only, and comorbid chronic pain and depression (see Table 4). People with chronic pain only were more likely to be in the middleaged and oldest age groups $(\mathrm{OR}=.18 ; \mathrm{CI}=.06, .52 ; \mathrm{p}<.01$ and $\mathrm{OR}=.09 ; \mathrm{CI}=.03, .28 ; \mathrm{p}<.01$, respectively) and were also more likely to be women $(\mathrm{OR}=.32 ; \mathrm{CI}=.14, .72 ; \mathrm{p}<.05)$ than people with depression only.

\begin{tabular}{|c|c|c|c|c|c|c|}
\hline & \multicolumn{2}{|c|}{$\begin{array}{l}\text { Chronic Pain Only } \\
\text { vs. Depression Only } \\
\qquad(\mathrm{n}=186)\end{array}$} & \multicolumn{2}{|c|}{$\begin{array}{l}\text { Chronic Pain Only } \\
\text { vs. Comorbid } \\
(n=219)\end{array}$} & \multicolumn{2}{|c|}{$\begin{array}{l}\text { Depression Only } \\
\text { vs. Comorbid } \\
(n=127)\end{array}$} \\
\hline & OR & $95 \% \mathrm{CI}$ & OR & $95 \% \mathrm{CI}$ & OR & $95 \%$ CI \\
\hline \multicolumn{7}{|l|}{ Age } \\
\hline Old (60+) & .09 & $(.03, .28)$ & .16 & $(.06, .47)$ & \multicolumn{2}{|c|}{$2.77 \quad(.81,9.47)$} \\
\hline Middle (40-59) & .18 & $(.06, .52)$ & .94 & $(.37,2.44)$ & 5.53 & $(2.02,15.18)$ \\
\hline \multicolumn{7}{|l|}{ Young (18-39) } \\
\hline \multicolumn{7}{|l|}{ Gender } \\
\hline Female & .32 & $(.14, .72)$ & .88 & $(.42,1.83)$ & 2.84 & $(1.16,6.96)$ \\
\hline \multicolumn{7}{|l|}{ Male } \\
\hline \multicolumn{7}{|l|}{ Race } \\
\hline Caucasian & .72 & $(.20,2.53)$ & $.41^{\dagger}$ & $(.17,1.04)$ & .72 & $(.22,2.32)$ \\
\hline \multicolumn{7}{|l|}{ African American } \\
\hline \multicolumn{7}{|l|}{ Employment } \\
\hline Not full-time & 1.32 & $(.50,3.50)$ & 1.95 & $(.87,4.37)$ & 1.20 & $(.40,3.61)$ \\
\hline \multicolumn{7}{|l|}{ Full-time } \\
\hline \multicolumn{7}{|l|}{ Education } \\
\hline High school or less & .63 & $(.18,2.19)$ & 2.29 & $(.54,9.71)$ & 2.84 & $(.54,14.97)$ \\
\hline Post-high school degree & .86 & $(.22,3.30)$ & 1.85 & $(.39,8.85)$ & 1.74 & $(.29,10.38)$ \\
\hline Bachelor's degree & .18 & $(.03,1.13)$ & 1.71 & $(.35,8.39)$ & 11.73 & $(1.18,116.31)$ \\
\hline Post-bachelor's degree & & & & & & \\
\hline
\end{tabular}

Income 


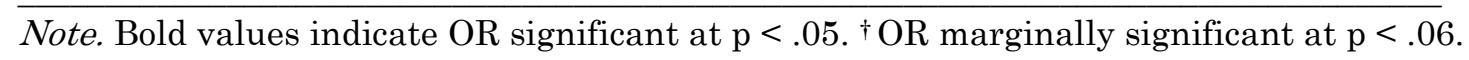

Table 4. Logistic Regression: Odds Ratios Comparing Diagnostic Groups.

Compared to persons with chronic pain only, persons with comorbid depression were less likely to be in the oldest age group $(\mathrm{OR}=.16 ; \mathrm{CI}=.06, .47 ; \mathrm{p}<.01)$. In addition, participants with comorbid depression were less likely to be Caucasian; however, this difference was only marginally significant $(\mathrm{OR}=.41 ; \mathrm{CI}=.17,1.04 ; \mathrm{p}<.06)$. Compared to persons with depression only, persons with depression and chronic pain were more likely to be women $(\mathrm{OR}=2.84 ; \mathrm{CI}=1.16,6.96 ; \mathrm{p}<.05)$ and middle-aged $(\mathrm{OR}=5.53 ; \mathrm{CI}=2.02,15.18 ; \mathrm{p}<.01)$. Finally, participants with both disorders and were more likely to have a bachelor's degree ( $\mathrm{OR}=11.73$; CI $=1.18,116.31 ; \mathrm{p}<.05$ ). However, the small sample size of reference group (i.e., post-bachelor's degree; $n=8$ ) for this analysis suggested a spurious result. This was confirmed when the analysis was rerun with the reference group consisting of bachelor's and post-bachelor's degrees; age and gender results remained whereas education was no longer significant.

\section{Discussion}

The goals of this study were to estimate the prevalence rates and risk factors of chronic pain and its comorbidity with depression in a community sample. The prevalence of chronic pain in this sample was $21.9 \%$, which was within the range that would be expected when compared to community studies using similarly stringent definitions of chronic pain [11,29]. Most of the chronic pain conditions were roughly classified as musculoskeletal and the most common sites of chronic pain included the lower back, knee, hip, and ankle/foot. These two findings are not surprising given the age distribution in the current study. Indeed, Helme and Gibson [19] found that some types of pain, including joint pain, increase with age. The problems and pain sites cited by many of the participants with pain are typically associated with less mobility. Thus, a substantial number of people living in the community may find simple tasks like walking and getting out of bed, painful, if not difficult.

In the current study, approximately $35 \%$ of the people with chronic pain also had a probable diagnosis of depression. This rate is somewhat higher than the prevalence of depression in other community studies of chronic pain (11-20\%) [11, 29] perhaps because these other studies focused on specific types of chronic pain (e.g., back pain [11]). In contrast, the current rate was lower than rates 
found in specialty samples (e.g., [2]), which might be more disabled by pain and depression. Chronic pain may impact mood because it is a chronic stressor as suggested by research showing that approximately $90 \%$ of patients with chronic pain develop depressive symptoms at the same time or after the chronic pain diagnosis [31]. However, the temporal relationship between chronic pain and depression was not investigated in the current study.

Depression in the context of chronic pain was not associated with certain types of pain. Specifically, among those with chronic pain, neither the approximate designation of musculoskeletal pain nor the site of pain was associated with depression. This is surprising because pain in sites most likely to affect mobility (e.g., hip, knee) could be expected to result in activity restriction, which in turn has been found to increase the risk of depression [35]. Perhaps, chronic pain regardless of site or type results in changes in other forms of activity (e.g., social interaction) that might be correlated with distress.

A number of demographic risk factors were investigated as correlates of chronic pain, depression, and comorbid chronic pain and depression. Older age was generally related to chronic pain with middle-aged participants being more likely to experience comorbid chronic pain and depression. In analyses comparing diagnostic groups, older and middle-aged participants were more likely to have chronic pain than depression. The oldest participants with pain were less likely to have comorbid depression whereas middle-aged participants with depression were more likely to have chronic pain. Similarly, a study of chronic back pain in the community showed that participants with comorbid pain and depression were younger than pain participants without depression [11]. Taken together, these results show that older age is a risk factor for chronic pain but not necessarily depression in pain. Depression tends to decrease with age [22] whereas pain tends to increase with age $[6,21,33]$. These patterns, which may be associated with important family and work role changes, may result in an overlap of the two conditions in middle age.

Female participants were more likely to report chronic pain with or without depression compared to the healthy participants in the sample. This finding is consistent with research showing that the prevalence of pain is typically higher among women[ 6, 10, 32, 34]. However, among participants with chronic pain, men and women were equally likely to be depressed, which is consistent with a study of outpatients [2]. Other comparisons among diagnostic groups revealed that women were more likely to have chronic pain alone than depression alone. However, depressed women were more likely to have chronic pain rather than depression alone. This constellation of findings suggests that while chronic pain may not be more depressogenic for women, depression may be associated with the development of chronic pain problems in women. The correlational nature of this study 
precludes conclusions about causal relationships but research has demonstrated that depression can increase one's vulnerability of experiencing persistent pain [25].

African Americans were at an increased risk for comorbid chronic pain and depression when examining the entire sample. Furthermore, among persons with chronic pain, Caucasians were more slightly likely than African Americans to have chronic pain without depression. Thus, African Americans with pain were more likely to have depression than Caucasians with pain. While it is difficult to draw firm conclusions given the marginal significance of the latter finding as well as the small proportion of African Americans in the current sample, the current findings support previous research showing that African Americans with chronic pain tend to report more depressive symptoms than Caucasians [15]. The fact that the regression analyses included other variables means that these differences in self-identified racial group were not due to possible socioeconomic differences between racial groups. As researchers have suggested, racial group differences may be due to a variety of factors including coping strategies [8, 13, 18], which were not a part of the current investigation.

Some socioeconomic variables (i.e., education, employment) increased the risk of chronic pain and comorbidity compared to participants without pain or depression. This finding supports research showing that education and employment indicators are associated with chronic pain [5, 6, 11]. In contrast, there were no stable socioeconomic differences among diagnostic groups. Occupational factors such as physically demanding work and poor or no health insurance may account for the link between low socioeconomic status and pain [30]. Similarly, socioeconomic status is associated with depression [36], possibly because of the financial strain and stress. It is also possible that pain and depression make it difficult to hold a job. Income was not a significant risk factor in this study, possibly because individual rather than household income was assessed. The lack of socioeconomic differences among diagnostic groups might also be attributed to the manner in which some of the variables (e.g., income, education) were categorized.

The findings from this study must be interpreted in light of sampling limitations. For instance, only home phone numbers were selected. College students living in residence halls and persons in nursing homes as well as participants using a cellular phone as their primary phone would not have been called. Second, some sub-populations may be more likely to be home and respond to a telephone interview, such as caretakers of small children, retirees, or people who are disabled because of depression or pain. Third, the response rates were slightly lower compared to other random digit dialing pain studies, which obtained response rates of at least 37\% [5, 9]. Thus, concerns about sample bias must be addressed by other studies. Finally, the sample was restricted to one Midwestern state in the U.S.A., which has traditionally had a manufacturing-based economy. 
Regarding other limitations, respondents with chronic pain who had not received a diagnosis would have been counted toward the healthy or depression only groups whereas depression due to a general medical condition or substance use could not be ruled out. Also, some participants may have been concerned with confidentiality if other people were home. However, the rates of chronic pain and depression for the current sample reflect rates found in the general population [22, 26, 29], suggesting that these issues minimally impacted the results. The exact onsets of chronic pain and depression as well as treatment types were not assessed. Future research should assess such information so that the temporal relationships between these variables can be better understood. Finally, participants dropped from the regression analyses, mostly due to missing demographic data, were more likely to be found in non-depressed group. It is not clear why such differences should occur when the demographic information was assessed prior to questions regarding pain or mood.

Nevertheless, our findings build on the existing literature by examining pain that is persistent for at least 6 months as well as depressive symptoms derived from diagnostic criteria. This study also investigated the risk factors of chronic pain as well as comorbid chronic pain and depression. Approximately 1 in 5 people in the community report chronic pain. Middle-aged and older persons, women, those working less than full-time, and those having less than a post-bachelor's degree appear to be most likely to have a chronic pain diagnosis. Approximately 1 in 3 people in the community with chronic pain also report depression. Given these high numbers, clinicians are encouraged to screen for depression among all their patients with chronic pain and to pay particular attention to screening younger and possibly, African American pain patients, for whom the risk of comorbid depression was greatest. Public health campaigns may be needed to educate the community about the extent of depression in chronic pain and offer ways to find treatment regardless of insurance status. Improved access to care is essential given the sheer number of persons living in the community with chronic pain, depression, or both conditions. 


\section{References}

[1] American Academy of Orthopaedic Surgeons: Musculoskeletal conditions in the United States. American Academy of Orthopaedic Surgeons Bulletin 47: 34-36, 1999.

[2] Arnow BA, Hunkeler, E.M., Blasey, C.M., Lee, J., Constantino, M.J., Fireman, B., Kraemer, H.C., Dea, R., Robinson, R., \& Hayward, C.: Comorbid depression, chronic pain, and disability in primary care. Psychosomatic Medicine 68: 262-268, 2006.

[3] American Psychiatric Association. Diagnostic and Statistical Manual of Mental Disorders DSM-IV-TR. Fourth ed. 2000, Washington DC: American Psychiatric Association.

[4] Banks SM, Kerns RD: Explaining high rates of depression in chronic pain: A diathesis-stress framework. Psychological Bulletin 119: 95-110, 1996.

[5] Blyth FM, March LM, Brnabic AJ, Cousins MJ: Chronic pain and frequent use of health care. Pain 111: 51-58, 2004.

[6] Blyth FM, March LM, Brnabic AJM, Jorm LR, Williamson M, Cousins MJ: Chronic pain in Australia: a prevalence study. Pain 89: 127-134, 2001.

[7] Cano A, Gillis M, Heinz W, Geisser M, Foran H: Marital functioning, chronic pain, and psychological distress. Pain 107: 99-106, 2004.

[8] Cano A, Mayo A, Ventimiglia M: Coping, Pain Severity, Interference, and Disability: The Potential Mediating and Moderating Roles of Race and Education. Journal of Pain 7: 459-468, 2006.

[9] Chung JW, Wong TK: Prevalence of pain in a community population. Pain Medicine 8: 235-242, 2007.

[10] Cunningham LS, Kelsey JL: Epidemiology of musculoskeletal impairments and associated disability. American Journal of Public Health 74: 574-579, 1994.

[11] Currie SR, Wang J: Chronic back pain and major depression in the general Canadian population. Pain 107: 54-60, 2004.

[12] Demyttenaere, Koen, Bruffaerts R, Lee S, Posada-Villa J, Kovess V, Angermeyer MC, Levinson D, de Girolamo G, Nakane H, Mneimneh Z, Lara C, de Graff R, Scott KM, Gureje O, Stein DJ, Haro JM, Bromet EJ, Kessler RC, Alonso J, von Korff M: Mental disorders among persons with chronic back or neck pain: Results from the world mental health surveys. Pain 129: 332-342, 2007.

[13] Edwards CL, Fillingim RB, Keefe F: Race, ethnicity and pain. Pain 94: 133-137, 2001.

[14] First M, Spitzer, L., Gibbon, M. \& Williams, J. Structured Clinical Interview for Axis I DSM-IV Disorders (SCID), ed. AP Association. 1995, Washington, DC.

[15] Green CR, Ndao-Brumblay SK, Nagrant AM, Baker TA, Rothman E: Race, age, and gender influences among clusters of African American and White patients with chronic pain. Journal of Pain 5: 171-182, 2004.

[16] Greenberg PE, Birnbaum, H.G., Lowe, S.W., \& Corey-Lisle, P.K.: The economic burden of depression in the United States: How did it change between 1990 and 2000? Journal of Clinical Psychiatry 64: 14651476, 2003.

[17] Gureje O, von Korff M, Simon GE, Gater R: Persistent pain and well-being: A world health organization 
study in primary care. JAMA 280: 147-151, 1998.

[18] Hastie BA, Riley JL, Fillingim RB: Ethnic differences in pain coping: Factor structure of the Coping Strategies Questionnaire and Coping Strategies Questionnaire-Revised. Journal of Pain 5: 304-316, 2004.

[19] Helme RD, Gibson, S.J.: The epidemiology of pain in elderly people. . Clinics in Geriatric Medicine 17: 417-431, 2001.

[20] Husain MM, Rush AJ, Trivedi MH, McClintock SM, Wisniewski SR, Davis L, Luther JF, Zisook S, Fava M: Pain in depression: STAR*D study findings. Journal of Psychosomatic Research 63: 113-122, 2007.

[21] Jakobsson U, Klevsgard, R., Westergren, A., \& Hallberg, I.R: Old people in pain: a comparative study. Journal of Pain and Symptom Management 26: 625-636, 2003.

[22] Kessler RC, Berglund P, Demler O, Jin R, Merikangas KR, Walters EE: Lifetime prevalence and age-ofonset distributions of DSM-IV disorders in the National Comorbidity Study replication. Archives of General Psychiatry 62: 593-602, 2005.

[23] Magni G, Caldieron C, Rigatti-Luchini S, Merskey H: Chronic musculoskeletal pain and depressive symptoms in the general population. An analysis of the 1st National Health and Nutrition Examination Survey data. Pain 43: 299-307, 1990.

[24] Magni G, Marchetti M, Moreschi C, Merskey H, Rigatti-Luchini S: Chronic musculoskeletal pain and depressive symptoms in the National Health and Nutrition Examination I. Epidemiologic Follow-up Study. Pain 53: 163-168, 1993.

[25] Magni G, Moreschi C, Rigatti-Luchini S, Merskey H: Prospective study on the relationship between depressive symptoms and chronic musculoskeletal pain. Pain 56: 289-297, 1994.

[26] McWilliams LA, Cox BJ, Enns MW: Mood and anxiety disorders associated with chronic pain: an examination in a nationally representative sample. Pain 106: 127-133, 2003.

[27] Mossey JM, Gallagher RM: The longitudinal occurrence and impact of comorbid chronic pain and chronic depression over two years in continuing care retirement community residents. Pain Medicine 5: 335-348, 2004.

[28] Moulin DE, Clark, A.J., \& Speechly, M.: Chronic pain in Canada - Prevalence, treatment, impact and the role of opioid analgesia. Pain Research Management 7: 179-184, 2002.

[29] Munce SEP, Stewart DE: Gender differences in depression and chronic pain conditions in a national epidemiologic survey. Psychosomatics 48: 394-399, 2007.

[30] Poleshuck EL, Green CR: Socioeconomic disadvantage and pain. Pain 136: 235-238, 2008.

[31] Romano JM, Turner JA: Chronic pain and depression: Does the evidence support a relationship? Psychological Bulletin 97: 18-34, 1985.

[32] Scudds RJ, Ostbye T: Pain and pain-related interference with function in older Canadians: the Canadian study of health and aging. . Disability and Rehabilitation 23: 654-664, 2001.

[33] Thomas E, Mottram, S., Peat, G., Wilkie, R., \& Croft, P.: The effect of age on the onset of pain interference in a general population of older adults: Prospective findings from the North Staffordshire Osteoarthritis Project (NorStOP). . Pain 129: 21-27, 2007. 
[34] Thomas E, Peat G, Harris L, Wilkie R, Croft PR: The prevalence of pain and pain interference in a general population of older adults: cross-sectional findings from the North Staffordshire Osteoarthritis Project (NorStOP). Pain 110: 361-368, 2004.

[35] Williamson GM, Schulz, R.: Pain, activity restriction, and symptoms of depression among communityresiding elderly adults. . Journal of Gerontology 47: 367-372, 1992.

[36] Zimmerman FJK, W.: Socioeconomic status, depression, disparities, and financial strain: What lies behind the income-depression relationship? Health Economics 14: 1197-1215, 2005. 